\title{
Dampak Prinsip-Prinsip Dasar ASEAN Terhadap Pola Kerjasama ASEAN Menghadapi Krisis Kudeta Myanmar
}

\author{
${ }^{1}$ Alvela S. Putri, ${ }^{2}$ Putri Jasmine, ${ }^{3}$ Riana Salma, ${ }^{4}$ Galang S. Bagasta, ${ }^{5} \mathrm{M}$. Padhil \\ Faturrahman \\ 1, 2,3,4,5 Program Studi Hubungan Internasional, Fakultas Ilmu Sosial dan Ilmu Politik, Universitas \\ Padjadjaran, Bandung - Indonesia \\ Email: alvela19001@mail.unpad.ac.id
}

\begin{abstract}
ASEAN as a regional organization has fundamental principles that underlie all activities carried out by member countries. This basic principle was recorded in the TAC (Treaty of Amity and Cooperation in South-East Asia) in 1976. However, in February 2021, one of the ASEAN member countries, Myanmar, was facing a crisis caused by a coup by the Myanmar military. ASEAN has a fundamental principle that keeps member countries from interfering with each other. However, the Myanmar crisis could affect other member countries and ASEAN cooperation. This study aims to determine the pattern of ASEAN cooperation in dealing with the Myanmar crisis under the basic principles of ASEAN. The research method used is a case study method with this type of research as qualitative research. This paper concludes that ASEAN principles which contrasting to the issues that currently occur make it difficult for ASEAN to make a foreign policy-making approach to the issue of the Myanmar military coup. In addition, this paper also concludes that to overcome the limits given by these basic principles, ASEAN takes an approach through the ASEAN Way of Diplomacy.
\end{abstract}

Keywords: ASEAN, Foreign Policy, Myanmar, Regional

\begin{abstract}
Abstrak
ASEAN sebagai organisasi regional memiliki prinsip-prinsip dasar yang melandasi segala kegiatan yang dilakukan oleh negara anggota. Prinsip dasar tersebut tercatat di dalam TAC (Treaty of Amity and Cooperation in South-East Asia) tahun 1976. Namun, pada bulan Februari tahun 2021, salah satu negara anggota ASEAN yaitu Myanmar tengah menghadapi krisis diakibatkan oleh kudeta oleh militer Myanmar. ASEAN memiliki prinsip dasar yang menahan negara anggota untuk saling mengintervensi satu sama lain. Akan tetapi, krisis Myanmar dapat mempengaruhi negara anggota lainnya dan kerjasama ASEAN. Penelitian ini bertujuan untuk mengetahui bagaimana pola kerjasama ASEAN dalam menghadapi krisis Myanmar dibawah prinsip dasar ASEAN. Metode penelitian yang digunakan adalah metode studi kasus dengan jenis penelitian sebagai penelitian kualitatif. Tulisan ini berkesimpulan bahwa prinsip-prinsip ASEAN yang kontras terhadap isu yang terjadi membuat ASEAN kesulitan dalam melakukan pendekatan pengambilan kebijakan luar negeri untuk menangani isu kudeta militer Myanmar. Selain itu, tulisan ini juga menyimpulkan bahwa untuk mengatasi batas yang diberikan prinsip-prinsip dasar tersebut ASEAN melakukan pendekatan melalui $A S E A N$ W ay of Diplomacy.
\end{abstract}

Kata Kunci: ASEAN, Kebijakan Luar Negeri, Myanmar, Regional 


\section{PENDAHULUAN}

Pada tahun 1967 ASEAN dibentuk dengan tujuan untuk meningkatkan ekonomi, sosial, kultur, edukasi, stabilitas sub kawasan dan menjunjung perdamaian dengan mengikuti aturan dari PBB (ASEAN, n.d.). Selain maksud dan tujuan, ASEAN juga memiliki prinsip-prinsip dasar yang seperti menjadi fondasi di dalam kegiatan diplomasi yang dilakukan oleh negara anggota. TAC (Treaty of Amity and Cooperation in Southeast Asia) merupakan perjanjian yang dibentuk pada tahun 1976 dan mengandung 6 prinsip dasar yang dipegang oleh ASEAN hingga saat ini. Prinsip yang pertama adalah prinsip untuk saling menghormati antar sesama anggota, kemudian prinsip kedua menekankan mengenai hak setiap negara anggota untuk memimpin negaranya tanpa ada campur tangan dari anggota lain. Prinsip ketiga adalah prinsip yang cukup terkenal dari ASEAN yaitu prinsip non-intervensi dalam mengurus atau menghadapi masalah internal suatu negara anggota. Prinsip keempat berisikan solusi damai di dalam sebuah perbedaan maupun perselisihan antar negara anggota dan prinsip yang terakhir adalah prinsip kerjasama ASEAN yang efisien (ASEAN, n.d.).

Namun, pada awal Februari ini telah terjadi sebuah krisis yang tak terduga yang menimpa salah negara anggota ASEAN yaitu Myanmar. Pada tanggal 1 Februari Myanmar mengalami kudeta oleh pihak militer Myanmar dan menahan pemimpin Myanmar yang baru saja terpilih-Aung San Suu Kyi (BBC, 2021). Kudeta ini menyebabkan demo besar-besaran oleh rakyat Myanmar dan walaupun cukup terkendali di awal masa demo, tetapi saat ini demo tersebut telah memakan banyak korban diakibatkan oleh tanggapan dalam bentuk kekerasan dari pihak militer Myanmar (Goldman, 2021). Goldman (2021) juga menjelaskan bahwa kudeta yang terjadi di Myanmar dipicu oleh ketidakpercayaan dari pihak militer terhadap hasil pemilu yang dimenangkan oleh partai Aung San Suu Kyi. Pihak militer Myanmar merasa bahwa terjadi kecurangan di dalam pemilu tersebut.

Kudeta di Myanmar ini tentu saja merupakan masalah internal negara yang dimana tertulis di dalam perjanjian TAC bahwa anggota ASEAN memiliki prinsip untuk membiarkan negara anggota mengurus negaranya sendiri tanpa campur tangan negara lain dan anggota ASEAN lainnya tidak boleh melakukan intervensi terhadap urusan internal negara anggota ASEAN. Namun, dengan adanya kekerasan yang terjadi kepada pengunjuk rasa di Myanmar 
dan mengakibatkan puluhan masyarakat kehilangan nyawa merupakan sebuah pelanggaran internasional dan HAM. Menteri Luar Negeri Indonesia-Retno Marsudi kini tengah bergerak untuk mendorong kesepakatan antara negara anggota ASEAN agar dapat membantu Myanmar keluar dari keadaan genting yang kini mereka hadapi (Strangio, 2021). Tentu saja inisiatif tersebut terdengar bertentangan dengan beberapa prinsip dasar yang dipegang oleh ASEAN sejak tahun 1976 dimana salah satu prinsip yang paling terkenal dan menjadi ciri khas ASEAN adalah prinsip non intervensi antar sesama anggota ASEAN. Sehingga, penelitian ini disusun dengan didasari pertanyaan mengenai bagaimana pola kerjasama ASEAN dalam menghadapi krisis kudeta Myanmar mengingat prinsipprinsip ASEAN yang menegaskan bahwa tidak boleh ada ikut campur dalam permasalahan negara anggota ASEAN lainnya.

Untuk menjawab pertanyaan tersebut maka penulis akan memulai penelitian dengan menjelaskan sejarah ASEAN disertai prinsip-prinsip dasar yang mengikatnya dan dilanjutkan dengan melihat bagaimana pola kerja sama ASEAN selama ini di bidang politik, ekonomi, dan keamanan bersama. Dengan berlakunya prinsipprinsip dasar ASEAN membuat organisasi regional ini memiliki cara diplomasinya tersendiri dan seringkali disebut sebagai ASEAN Way of Diplomacy, hal tersebut kemudian akan penulis jelaskan di dalam pembahasan disertai mekanisme bagaimana diplomasi ASEAN bekerja terhadap sesama negara anggota. Pembahasan selanjutnya akan beralih menjelaskan lebih dalam mengenai kudeta militer di Myanmar dan penulis akan menutup pembahasan dengan menjelaskan dampak dari prinsip-prinsip dasar ASEAN dan cara diplomasi ASEAN yang mempengaruhi pola kerjasama ASEAN dalam menghadapi krisis yang sedang dihadapi negara anggota mereka yaitu Myanmar. Tulisan ini memiliki tujuan untuk mengetahui bagaimana ASEAN menghadapi krisis kudeta Myanmar dengan keterbatasan kerjasama yang diakibatkan oleh prinsip-prinsip dasar ASEAN yang mengikat.

\section{TINJAUAN LITERATUR}

Terdapat beberapa penelitian kualitatif yang sudah membahas mengenai topik pola kerjasama ASEAN dan prinsip-prinsip dasar ASEAN dalam menghadapi isu yang berhubungan dengan negara anggotaMyanmar. Rukun Katanyuu melakukan penelitian dengan judul Beyond Non-Interference in ASEAN: The Association's Role in Myanmar's National Reconciliation and Democratization' pada tahun 2006. Pada penelitiannya, 
Katanyuu bertujuan untuk menganalisa bagaimana kebijakan non-intervensi yang dimiliki ASEAN untuk lebih toleran terutama ketika dihadapi dengan masalah Burma dan Thailand pada tahun 2001 (Katanyuu, 2006, p. 1-6). Katanyuu (2006:22) mendapatkan kesimpulan bahwa dengan taruhan eksistensi ASEAN sebagai sebuah organisasi regional yang memiliki martabat tinggi di dalam bidang ekonomi dan keamanan jika membiarkan isu Burma-Thailand begitu saja dan dengan dorongan dari berbagai pihak Internasional membuat ASEAN pada saat itu harus campur tangan terhadap urusan internal Burma melalui ASEAN Summit ke-11 pada tahun 2005.

Ludo Cuyvers juga menjelaskan pada tahun 2019 di dalam tulisannya yang berjudul 'The 'ASEAN Way' and ASEAN's Development Gap With Cambodia, Laos, Myanmar and Vietnam: A Critical View' mengenai bagaimana ASEAN Way menjadi sebuah strategi di dalam pengambilan keputusan untuk melakukan sebuah kebijakan maupun diplomasi oleh ASEAN dalam menutup gap pembangunan antara negara ASEAN lainnya dengan Cambodia, Laos, Myanmar dan Vietnam (Cuyvers, 2019, p. 1). Walaupun pada tulisannya Cuyvers lebih berfokus terhadap dampak ASEAN Way terhadap bidang ekonomi, namun disini
Cuyvers menjelaskan (2019:17) bahwa dominasi ASEAN Way dalam pembentukan keputusan ASEAN justru membuat pengembangan yang merata antar negara ASEAN dapat dikatakan menjadi cukup sulit terutama dengan kebijakan nonintervensi yang pada akhirnya membuat pengambilan keputusan ASEAN dalam mengatasi situasi antar anggota menjadi bertele-tele.

Berdasarkan contoh tulisan yang berhubungan mengenai prinsip ASEAN hingga kerjasama ASEAN melalui $A S E A N$ Way yang telah dijabarkan sebelumnya, banyak dari penelitian tersebut sudah menganalisis mengenai kebijakan dari prinsip ASEAN terutama kebijakan nonintervensi dan juga menganalisis bagaimana pengambilan keputusan ASEAN melalui $A S E A N W$ ay dengan beragam studi kasus dan melihat dari berbagai bidang mulai dari politik hingga ekonomi. Namun, belum ada penelitian yang meneliti hubungan kedua topik tersebut ke dalam isu yang baru-baru ini terjadi dan masih berlangsung yaitu kudeta militer di Myanmar.

\section{METODE DAN TEORI}

\section{Metode}

$\begin{array}{lrr}\text { Penelitian ini } & \text { merupakan } \\ \text { penelitian kualitatif } & \text { dengan } \\ \text { menggunakan metode studi kasus. Di }\end{array}$


dalam penelitian ini studi kasus yang terkait akan dianalisis secara tajam menggunakan faktor-faktor yang bersangkutan untuk membentuk kesimpulan yang cermat. Penulis akan menggunakan data sekunder sebagai referensi yang berasal dari berbagai publikasi oleh organisasi internasional maupun buku serta artikel jurnal. Selain itu, penulis juga akan menggunakan data dan berita yang dipublikasi secara daring di internet sebagai sumber referensi. Penelitian ini akan dianalisis menggunakan teknik studi literatur.

\section{Teori Regionalisme}

Sistem hubungan internasional saat ini telah tentunya telah berkembang dan berubah secara drastis khususnya pasca perang dingin. Hal tersebut telah mendorong berbagai kawasan di dunia diwarnai polarisasi dan mempertegas kembali keberadaanya, Dunia Maju dan Dunia Berkembang. Permasalah dalam sektor ekonomi, keamanan, dan politik akan selalu muncul dan seringkali tidak dijumpai keadilan di dalamnya. Dalam mengakomodir perbedaan kepentingan tersebut, berbagai negara pun melakukan berbagai upaya yang umumnya bersifat regional, atau sering disebut sebagai regionalisme.

Regionalisme mengacu pada gagasan politik dan kognitif dalam pembentukan suatu daerah. Biasanya dikaitkan dengan program formal, dan sejak pertengahan 1980-an telah terjadi ledakan program regional tersebut dalam skala global. Perluasan dan pendalaman European Union (EU) mungkin merupakan contoh yang paling jelas, tetapi regionalisme juga terbukti dalam revitalisasi atau perluasan banyak proyek regional lainnya di seluruh dunia, seperti African Union (AU), the Association of Southeast Asian Nations (ASEAN), the Economic Community of West African States (ECOWAS), the North American Free Trade Agreement (NAFTA), Southern African Development Community (SADC), Southern Common Market (Mercosur) dan, baru-baru ini, Union of South American Nations (UNASUR) (Söderbaum, 2014). Kerjasama dalam region sendiri mampu meningkatkan regionalisasi dalam sebuah permasalahan. Negara-negara di seluruh dunia pun telah mengakui bahwa regionalisme dibutuhkan dalam menghadapi tantangan-tantangan di masa depan.

Laju regionalisme sendiri telah melalui beberapa gelombang. Gelombang pertama sendiri terjadi pada awal tahun 1800-an hingga 1900an yang ditandai dengan sentralisasi aktivitas di kawasan Eropa melalui ekonomi serta perdagangannya. Kemudian gelombang kedua ditandai dengan efek krisis eropa (great depression) yang mana setelah itu 
diperoleh lah kebijakan proteksionis hingga muncul wacana perdagangan kawasan dikarenakan kegagalan pada sektor perdagangan multilateral.

Selanjutnya gelombang ketiga yang ditandai dengan meningkatnya perdagangan internasional yang terjadi di Asia Timur dan Eropa Barat yang dicirikan dengan munculnya blok-blok perdagangan di beberapa kawasan tersebut. Gelombang keempat regionalisme sendiri dicirikan dengan munculnya kerjasama-kerjasama ekonomi antar negara berkembang, penguatan kerjasama multilateral dan penguatan investasi asing melalui dukungan lembaga multilateral (Edward D. Mansfield; Helen V. Milner, 2003). Sedangkan menurut Fawcett (1992), perkembangan regionalisme hanya hanya terbagi menjadi dua yaitu regionalisme baru dan lama. Regionalisme lama ditandai dengan kerjasama regional yang berorientasi terhadap hal yang dilakukan oleh negara-negara dengan level yang sama melalui proses politik, sedangkan regionalisme baru berorientasi ke luar, dengan kata lain dilakukan oleh negara-negara yang bervariasi dan melalui proses ekonomi.

Berakhirnya perang dingin diikuti dengan proses globalisasi telah menjadikan masa-masa pada tahun 90an memicu terjadinya akselerasi kerjasama kawasan (John Baylis; Steve Smith, 2005). Kondisi ini oleh beberapa ilmuwan disebut sebagai new regionalism. Dalam hal ini terdapat beberapa indikator yang mampu menjelaskan perkembangan regionalisme. Yang pertama adalah dengan adanya sebuah kawasan (region), lalu yang kedua adalah dengan meningkatnya ketertarikan antar satu negara dengan negara lainnya yang berada dalam satu kawasan demi mengembangkan kepentingan bersama, dan yang terakhir adalah dengan berkembangnya organisasi internasional sebagai sebuah wadah atau media dalam pembentukan aturan kerja bersama (Smith, 1997). Selain itu, regionalisme juga dapat dilihat dari dua sisi, sisi pertama adalah eksternal yang mana regionalisme adalah salah satu reaksi dari proses global. Dari sisi internal, regionalisme dipandang sebagai akses dari perkembangan dinamika internal suatu kawasan yang dipengaruhi oleh main actors dari kawasan tersebut baik dari eksternal maupun internal.

\section{Teori Kebijakan Luar Negeri}

Kebijakan luar negeri terbentuk dari adanya kepentingan untuk suatu aktor memasuki dunia politik yang merabah secara internasional. Terciptanya kebijakan luar negeri juga didasari oleh kepentingan yang dimiliki suatu negara dalam memenuhi kebutuhan negaranya sendiri yang tidak dimiliki di wilayah cangkupannya 
sendiri. Kebijakan luar negeri juga bisa menjadi representasi atas pernyataan sikap terhadap isu-isu internasional. Pembentukan kebijakan luar negeri bisa menjadi instrumen yang digunakan dalam upaya perlindungan diri suatu negara dari segala bentuk ancaman yang bisa saja datang dari pihak eksternal. Tanpa adanya kebijakan luar negeri, suatu negara tidak akan pernah bisa berinteraksi dengan negara-negara lain secara global. Pendekatan negara terhadap negara lain sangat diperlukan karena arus globalisasi yang menuntut masyarakat internasional yang lebih maju dan kebutuhan-kebutuhan baru yang beragam.

Setiap negara yang akan berhubungan dengan negara lain secara global pastinya akan memerlukan sebuah kebijakan luar negeri sebagai dasar dalam pengambilan tindakan. Kebijakan luar negeri sendiri didefinisikan sebagai sebuah kebijakan yang terbentuk dengan dasar untuk mencapai tujuan, pengambilan keputusan, nilai, dan tindakan yang akan diambil oleh aktor negara yang akan berhubungan dengan pihak eksternal (Wabber \& Smith, 2002, p. 11-12). Ada juga definisi tentang kebijakan luar negeri adalah suatu kebijakan pemerintah suatu aktor negara yang memiliki wewenang terhadap lingkungan internasional dan didasari oleh nilai-nilai dan kepentingan yang dimiliki negara itu sendiri.

Hal-hal yang mempengaruhi pembentukan kebijakan luar negeri bisa dipengaruhi oleh keadaan eksternal dan internal suatu negara. Perancangan kebijakan luar negeri memiliki dasar atas bentuk pemerintahan dan ideologi yang dianut oleh suatu negara. Dengan mengenali apa saja yang terkandung dalam dasardasar yang dimiliki negara sendiri, suatu kebijakan dapat terbentuk dengan mempertahankan nilai-nilai dasar negara yang ada dan memperjuangkan tujuan nasional secara spesifik yang dituang dalam terminologi kepentingan nasional yang ingin dicapai suatu negara (Rosenau, 1999, p. 5). Menurut Rosenau juga menjelaskan bahwa kebijakan luar negeri dibentuk bertujuan untuk memperoleh keuntungan yang terdapat dari lingkungan politik global.

Kebutuhan internal dan eksternal suatu negara bisa meliputi kapabilitas yang dimiliki suatu negara, intuisi yang aktif, aktivitas rutin yang dilakukan suatu negara, konflik yang terjadi internal maupun eksternal, kebudayaan yang dianut, atribut nasional yang dimiliki, dan aspirasi yang bisa didapatkan dari seluruh aspek internal maupun eksternal. Bentuk kebutuhan ini dalam pembentukan kebijakan luar negeri tercipta dari pertimbangan yang 
ditujukan untuk menjaga identitas sosial, geografis, dan hukum yang berlaku.

Sumber yang terkandung di dalam kebijakan luar negeri menurut Howard Lentner (1974:105-171) terbagi dua kelompok, yaitu determin luar negeri dan determinan domestik. Determin luar negeri menggambarkan tentang sistem internasional yang ada dalam situasi di kurun waktu tertentu. Sistem internasional mengatur bagaimana gambaran para aktor global saling berinteraksi. Situasi yang sedang terjadi yang bisa saja mencangkup dan tidak mencangkup apa yang ada dalam sistem internasional. Pemahaman situasi global menjadi dasar yang digunakan dalam menganalisa lingkungan eksternal untuk menciptakan pembuatan keputusan yang relevan. Determinan domestik merupakan representasi atas nilai-nilai yang dimiliki di dalam negeri. Determinan domestik berisikan aspekaspek geografis, gaya berpolitik, kultur yang berlaku, dan sikap atas persepsi jangka panjang serta beberapa faktor ketidak sengajaan yang bisa saja terjadi.

\section{HASIL DAN PEMBAHASAN}

\section{Prinsip-prinsip Dasar ASEAN}

ASEAN atau Perhimpunan Bangsa-Bangsa Asia Tenggara menurut buku "Ayo Kenali ASEAN" yang dibentuk oleh Sekretariat
Nasional ASEAN - Indonesia (2018:11) merupakan sebuah organisasi kawasan dari regional Asia Tenggara yang menjadi wadah bagi 10 negara untuk saling bekerja sama satu sama lain dalam satu visi yang sama. Organisasi ini terbentuk sejak tanggal 8 Agustus 1967 yang kala itu dicetuskan oleh 5 negara yaitu Indonesia, Malaysia, Singapura, Filipina, dan Thailand yang mana kala itu hadir dalam deklarasi Bangkok dan lalu menandatangani tangani piagam ASEAN oleh kelima negara tersebut. Seiring berjalannya waktu, beberapa negara Asia Tenggara lainnya mulai bergabung dalam ASEAN seperti Negara Brunei Darussalam, Vietnam, Laos, Myanmar, dan Kamboja. Pembentukan Organisasi Internasional regional Timur tenggara pada saat tahun 60-an, dunia masih dinilai rawan akan konflik Ideologi dan militer. Pembentukan ASEAN ini berdasarkan visi untuk menciptakan kawasan regional yang terhindar dari pengaruh konflik diluar Asia Tenggara.

Dalam Piagam ASEAN terdapat 14 prinsip dasar yang dimiliki oleh ASEAN itu sendiri. Prinsip ini dipegang teguh oleh tiap anggota ASEAN dalam menjalankan tugasnya sebagai anggota ASEAN dan menjadi karakteristik dari ASEAN itu sendiri (THE ASEAN CHARTER, 2015, p. 6). Terdapat beberapa prinsip yang mengedepankan rasa hormat terhadap 
perbedaan yang dimiliki setiap anggota ASEAN. Semua itu tertuang pada prinsip yang pertama, 6, 9, dan 12 yang mana dalam prinsip tersebut setiap anggota ASEAN harus memiliki rasa hormat terhadap kedaulatan sesama negara ASEAN, eksistensi tiap negara yang bebas dari campur tangan pihak eksternal, kebebasan fundamental dan hak asasi manusia, serta menghormati segala perbedaan mulai dari budaya, agama, dan segala kemerdekaan yang mana seluruh anggota ASEAN harus tetap menjaga persatuan satu sama lain. Tiap anggota yang telah bergabung dalam ASEAN juga harus berkomitmen kepada ASEAN dan bertanggung jawab secara kolektif yang bertujuan demi menciptakan keamanan dan kemakmuran kawasan Asia Tenggara seperti yang tertuang dalam prinsip ke 2 .

Untuk mencapai perdamaian dalam kawasan dan terhindar dari konflik yang berkelanjutan, prinsip ke 3 menjelaskan tentang sikap setiap anggota ASEAN untuk menolak segala Agresi dan mendekati segala ancaman yang berlawanan dengan hukum Internasional yang berlaku seperti halnya yang tertuang dalam prinsip ke 8 yang tetap berpegang teguh terhadap hukum yang telah dibentuk tiap negara dan mengikuti prinsip-prinsip demokrasi agar tercipta pemerintahan yang baik untuk seluruh anggota ASEAN. Prinsip Keempat yang berisikan ketergantungan pada penyelesaian damai sengketa yang mana merupakan sebuah cara ASEAN dalam menyelesaikan konflik internal ini juga merupakan suatu bentuk usaha ASEAN dalam menciptakan lingkungan yang aman di Asia Tenggara. Kandungan yang terdapat didalam prinsip ke 7, 11, dan 13 juga bisa ditafsirkan sebagai usaha ASEAN untuk membentuk wilayah yang aman di Asia Tenggara. Jika terjadi suatu masalah yang mempengaruhi Asia tenggara maka dilaksanakan konsultasi kepada sesama anggota ASEAN. Menghindari segala kegiatan dan kebijakan yang mengancam ASEAN juga menjadi suatu peringatan bagi para anggota ASEAN. Para anggota ASEAN pun dianjurkan tetap membuka jalur komunikasi terhadap pihak eksternal tanpa adanya rasa diskriminatif terhadap pihak eksternal. Di Dalam prinsip kelima pun setiap anggota ASEAN tidak boleh ikut campur dalam hal yang berkaitan masalah internal suatu negara sesama anggota ASEAN demi menghormati kepentingan tiap negara anggota dan menghindari ketidak harmonisan dalam ASEAN.

ASEAN sebagai organisasi internasional regional tetap memiliki posisi yang berada dibawah PBB dan hukum internasional. Setiap anggota ASEAN tetap harus menaati apa yang terkandung di dalam piagam $\mathrm{PBB}$, 
hukum internasional, termasuk juga hukum humaniter internasional yang berlaku secara global seperti yang tercantum dalam prinsip ASEAN kesepuluh. Dan juga dalam membentuk ekonomi regional yang baik, ASEAN membentuk prinsip yang terakhir, yang mana menjelaskan bahwa setiap anggota ASEAN harus harus berpegang teguh terhadap aturan-aturan perdagangan multilateral dan rejim-rejim yang didasarkan pada aturan ASEAN dan berusaha untuk menghilangkan hambatan yang ada dalam integrasi ekonomi kawasan.

\section{Pola Kerjasama ASEAN}

ASEAN merupakan organisasi regional yang dibentuk berdasarkan kepentingan nasional bersama dengan tujuan meningkatkan pertumbuhan ekonomi, perkembangan sosial, politik serta keamanan. ASEAN sendiri telah berkembang menjadi sebuah organisasi dengan banyak pencapaian hingga saat ini. Sebagai organisasi yang mewadahi kerjasama negara-negara di kawasan Asia Tenggara dan sekitarnya, keberadaan ASEAN pastinya akan mendatangkan keuntungan bagi negara-negara anggotanya. Keuntungan tersebut dapat diwujudkan melalui kerjasama dalam berbagai bidang, yang diantaranya:

\section{Kerjasama Politik dan Keamanan (Political-Security Cooperation)}

Pengaturan kerja sama ASEAN di bidang politik serta keamanan dilakukan melalui Dewan Masyarakat Politik Keamanan ASEAN (ASEAN Political-Security Community Council) yang didukung oleh para pejabat tinggi di bidang politik serta keamanan. Pertemuan Dewan Masyarakat Politik. Pembentukan APSC ditujukan untuk mempercepat kerja sama politik dan keamanan di ASEAN dalam mewujudkan perdamaian di kawasan regional dan global (Kementerian Luar Negeri Indonesia, 2015). APSC ini bersifat terbuka, berdasarkan pendekatan keamanan yang komprehensif dan tidak ditujukan untuk membentuk suatu pakta pertahanan/aliansi militer maupun kebijakan luar negeri bersama. Pertemuan ini diselenggarakan minimal dua kali dalam setahun. Pertemuan pertama Dewan Masyarakat Politik Keamanan ASEAN (ASEAN Political-Security Community Councit) ini pertama kali diselenggarakan di Pattaya, Thailand pada tahun 2009.

Perwujudan Masyarakat PolitikKeamanan ASEAN sendiri didasarkan pada berbagai instrumen politik ASEAN yang telah ada seperti Piagam ASEAN, Deklarasi Kawasan Damai, Bebas, dan Netral (Zone of Peace, Freedom and Neutrality/ZOPFAN), Traktat Persahabatan dan Kerja Sama Negara-Negara ASEAN (Treaty of 
Amity and Cooperation in Southeast Asia/TAC), dan Zona Bebas Senjata Nuklir Asia Tenggara (Treaty on Southeast Asia Nuclear Weapon-Free Zone/SEANWFZ) termasuk Piagam PBB dan prinsip-prinsip hukum internasional terkait lainnya. Untuk mempromosikan komunitas berbasis norma serta nilai bersama, negaranegara anggota pun memperkuat kolaborasi politik. Mereka membentuk dan berbagi norma sebagaimana diilustrasikan dalam Perjanjian Amity dan Kerjasama, Perjanjian tentang Zona Bebas Senjata Nuklir Asia Tenggara, dan Deklarasi mengenai Perilaku Para Pihak di Laut Timur (ASEAN, 2009).

Stabilitas keamanan kawasan juga merupakan salah satu pilar utama dalam mewujudkan pembangunan Masyarakat ASEAN yang lebih baik. Selain itu, dalam sektor keamanan ASEAN sendiri membentuk Institute for Peace and Reconciliation (AIPR) sebagai institusi yang dimanfaatkan untuk penyelesaian konflik. AIPR diresmikan pada november 2012 dalam KTT ke-21 ASEAN di Phnom Penh. Dalam pelaksanaan tugasnya, AIPR memiliki Governing Council sebagai pengambil kebijakan serta Advisory Board. Beberapa hasil kerjasama ASEAN dalam sektor keamanan juga dapat dilihat dalam beberapa bidang. Dalam bidang pemberantasan kejahatan lintas negara,
ASEAN memiliki rencana aksi yang dikenal dengan Plan of Action to Combat Transnational Crime, yang dimaksudkan sebagai rencana dalam pengembangan suatu strategi kawasan terpadu dalam mencegah serta memberantas kejahatan lintas negara, yang terbagi dalam delapan prioritas diantaranya counter terrorism, illicit drugs trafficking, trafficking in persons, money laundering, arms smuggling, sea piracy, international economic crime, dan cyber crime (Kementerian Luar Negeri Indonesia, 2015).

Dalam bidang terorisme, ASEAN membentuk ASEAN Convention on Counter Terrorism (ACCT) pada 13 Januari 2007 di Cebu, Filipina. ACCT ini berlaku setelah enam negara yang terdiri dari Filipina, Thailand, Vietnam, Kamboja, Brunei dan Singapura meratifikasinya. Selanjutnya dalam bidang Perlindungan terhadap Perdagangan dan Penyelundupan Manusia (Trafficking in Persons/TIP) yang cukup mendapatkan perhatian juga penanganan serius oleh negaranegara anggota ASEAN. Pembentukan ACTIP ini bertujuan untuk menjadi landasan ASEAN dalam menangani kejahatan perdagangan orang serta meningkatkan kerjasama dalam konteks mitra wicara maupun ASEAN itu sendiri. Terakhir, dalam bidang keamanan maritim (Maritime Security) ASEAN telah membahas beberapa isu 
mengenai maritim yang dilakukan dalam beberapa mekanisme seperti ASEAN Maritime Forum (AMF), Expanded ASEAN Maritime Forum (EAMF), ASEAN Regional Forum (ARF), ASEAN Defence Ministerial Meeting (ADMM), ASEAN Defence Ministerial Meeting Plus (ADMM-Plus) dan 13 mekanisme lainnya.

\section{Kerjasama Ekonomi}

Ekonomi merupakan pilar terpenting dalam alur kerjasama ASEAN. Pilar ekonomi ini ditujukan untuk menciptakan pasar tunggal serta basis produksi yang ditandai dengan adanya barang, jasa, investasi, aliran bebas, modal dan tenaga kerja terampil yang nantinya akan meningkatkan daya saing regional, kemakmuran, dan daya tarik bagi para investor asing. Negaranegara ASEAN juga mempercepat implementasi dari perjanjian perdagangan bebas blok bersama mitra utamanya seperti Cina, Jepang, Korea, India, Selandia Baru dan Australia, dalam menyelesaikan perjanjian Kemitraan Ekonomi Komprehensif Regional agar mampu menciptakan ruang ekonomi yang terbuka di Asia Timur. Selain itu, para negara anggota ASEAN pun menjabarkan bahwa Masyarakat Ekonomi ASEAN (MEA) akan menjadi babak baru dalam perkembangan ekonomi negaranegara di Asia Tenggara serta memberikan peluang kerjasama ekonomi antar kawasan dalam skala yang jauh lebih luas lagi (Siow Yue Chia; Michael G. Plummer, 2015).

Pada tahun 1967 saat ASEAN pertama kali dibentuk, kerjasama ekonomi merupakan salah satu agenda utama yang perlu dikembangkan. Pada awalnya kerjasama ekonomi ini difokuskan terhadap programprogram pemberian preferensi perdagangan (preferential trade), usaha patungan (joint ventures), serta skema saling melengkapi (complementation scheme) antar pemerintah negara-negara anggota maupun pihak swasta di kawasan ASEAN, seperti ASEAN Industrial Projects Plan (1976), Preferential Trading Arrangement (1977), ASEAN Industrial Complementation scheme (1981), ASEAN Industrial Joint-Ventures scheme (1983), dan Enbanced Preferential Trading arrangement (1987). Saat negara-negara di belahan dunia berusaha melakukan upaya penghilangan hambatan ekonomi di tahun 80-an, negara ASEAN menyadari bahwa cara bekerjasama yang harus dilakukan adalah dengan saling membuka perekonomian mereka, agar terciptanya integrasi ekonomi kawasan yang baik (Indratno, 2009).

Dalam beberapa pertemuan Konferensi Tingkat Tinggi Perbara (ASEAN Summit/KT'T) yang dihadiri berbagai perwakilan negara ASEAN, telah menghasilkan beberapa program dalam sektor ekonomi yaitu, KTT ke- 
5 ASEAN di Singapura tahun 1992 telah ditandatangani Framework Agreement on Enhancing ASEAN Economic Cooperation sekaligus menandai dicanangkannya ASEAN Free Trade Area (AFTA) sebagai bentuk pengurangan tarif hambatan dan perbaikan kebijakan fasilitasi perdagangan. Pada KTTT ke-9 di Bali tahun 2003, ASEAN menyepakati pembentukan komunitas ASEAN yang salah satu pilarnya adalah Komunitas Ekonomi ASEAN (AEC) untuk menciptakan pasar tunggal dan basis produksi. Pada KTT ke-10 di Vientiane pada tahun 2004, ASEAN menyepakati Vientiane Action Program (VAP) yaitu panduan untuk mendukung implementasi pencapaian AEC di tahun 2020. Pada tahun 2006 di Malaysia, ASEAN Economic Ministers Meeting (AEM). Pada KTTT ASEAN di Cebu bulan Januari 2007 telah menyepakati "Declaration on the Acceleration of the Establishment of an ASEAN Community by 2015" yang berisi rencana strategis ekonomi ASEAN. Lalu terakhir, Pada KTT ASEAN Ke-13 di Singapura, bulan Nopember 2007, telah disepakati Blueprint for the ASEAN Economic Community (AEC Blueprint) yang akan digunakan sebagai peta kebijakan (roadmap) guna mentransformasikan ASEAN menjadi pasar tunggal dengan basis produksi kawasan yang kompetitif serta terintegrasi dengan ekonomi global (Indratno, 2009).

Sektor jasa pada kawasan Asia Tenggara telah menjadi faktor utama yang mempercepat pertumbuhan ekonomi di kawasan ini, saat sektor pertanian telah menurun dalam tujuh tahun terakhir. Pada 2012, sektor jasa berkontribusi bagi mayoritas GDP sepuluh negara ASEAN, rata-rata mulai dari 35 persen hingga lebih dari 60 persen dari GDP. Ekonomi ASEAN5 kini secara bertahap bergerak ke sektor tersier, sementara kelompok BCLMV Countries (Bangladesh, Cambodia, Lao PDR, Myanmar, dan Vietnam) tengah membangun sektor sekunder dan tersier di negeri masing-masing. Kesepakatan mengenai adanya pasar tunggal (MEA) yang dimulai pada tahun 205 diharapkan mampu mempermudah proses perdagangan barang dan jasa di kawasan Asia Tenggara. Berdasarkan riset International Labor Organization atau ILO, pada tahun 2014 mengungkapkan bahwa manfaat dari adanya pembukaan pasar tenaga kerja ini sangat besar. MEA diperkirakan akan mampu meningkatkan kesejahteraan 600 juta jiwa penduduk Asia Tenggara karena akan menciptakan jutaan lapangan kerja baru. Pada tahun 2015 ILO juga memprediksi bahwa permintaan 
tenaga kerja profesional akan naik 41\% atau sekitar 14 juta.

Dikarenakan terjadinya fenomena demographic boom, negaranegara anggota ASEAN sendiri memiliki potensi pertumbuhan yang tinggi. Pertumbuhan jumlah penduduk usia kerja produktif yang signifikan itu diiringi dengan tingkat kesejahteraan yang relatif lebih baik sehingga memicu terjadinya pertumbuhan tingkat konsumsi industri dan rumah tangga yang meningkat. Namun hal yang disayangkan adalah sebagian besar pertumbuhan tingkat konsumsi tersebut masih didominasi oleh barang-barang impor yang bukan hanya dapat berpengaruh terhadap keseimbangan nilai tukar namun juga dapat mengakibatkan membesarnya potensi terjadinya imported inflation (Siow Yue Chia; Michael G. Plummer, 2015).

\section{Diplomasi ASEAN Way}

Dalam melakukan interaksi dan pemecahan masalah, ASEAN memiliki cara tersendiri yang membuatnya berbeda dari organisasi regional lainnya yang dikenal dengan istilah ASEAN Way of Diplomacy. Kemunculan pola diplomasi ini merupakan hasil lebih lanjut dari implementasi poin poin dalam Treaty of Amity and Cooperation in Southeast Asia Indonesia, 24 Februari 1976 (ASEAN, 2016), yang memberi garis besar panduan anggota ASEAN dalam bertindak seperti prinsip nonintervensi dan saling menghormati batas wilayah dan kedaulatan masing masing. Setelah penandatangan perjanjian tersebut, banyak ahli yang mencoba menjelaskan apa itu ASEAN Way of Diplomacy yang pada akhirnya menurut Hiro Katsumata (2003:106), prinsip utama ASEAN Way terdiri dari empat poin yaitu the principles of non-interference in the internal affairs of other members, quiet diplomacy, the non-use of force, and decision-making through consensus. Poin pertama dari ASEAN Way yaitu the principles of non-interference in the internal affairs of other members memberikan batasan batasan yang jelas dalam pola kerjasama dan interaksi anggota ASEAN. Prinsip ini membuat dalam proses pengambilan kebijakan terkait isu atau keadaan di negara anggota lain harus dengan seizin negara bersangkutan dan negara lain tidak diperbolehkan mengambil sikap yang dirasa akan merusak rasa kebersamaan antar anggota ASEAN.

Kedua, prinsip quiet diplomacy yang menjadi salah satu cara negara anggota ASEAN melakukan interaksi yaitu dengan melaksanakan diplomasi untuk isu isu sensitif secara diam diam atau bersifat bilateral daripada melakukan diplomasi secara terang terangan seperti melaksanakan konferensi tingkat tinggi dan sejenisnya. Ketiga, prinsip the non-use of 
force yang pada dasarnya membuat hubungan anggota ASEAN menjadi lebih kekeluargaan dengan kepercayaan antar anggota, prinsip ini menghindari penggunaan kekuatan militer dalam pemecahan masalah ASEAN yang seharusnya dapat diselesaikan dengan poin terakhir yaitu decision-making through consensus. Dengan demikian, panduan dalam berinteraksi sesama anggota ASEAN menciptakan suasana politik yang damai di dalam region ini. Namun, prinsip ASEAN Way dianggap kurang berdampak besar dalam pemecahan isu sensitif karena prinsip ini cenderung menghasilkan penghindaran isu dengan alasan menjaga rasa kekeluargaan dalam keanggotaan ASEAN (Katsumata, 2003, 106).

\section{Mekanisme Diplomasi ASEAN Way Dengan Negara Anggota}

Pola interaksi ASEAN yang menggunakan prinsip ASEAN Way dapat dengan mudah kita temukan dalam konferensi tingkat tinggi dari ASEAN itu sendiri. Dapat kita lihat bahwa dalam KTT ASEAN prinsip ASEAN $W$ ay of Diplomacy sangat berpengaruh. Dalam KT'T ASEAN, negara anggota sangat menjaga pembahasan isu yang diangkat. Contohnya pada the 30th ASEAN Summit 2017 yang menyatakan pernyataan oleh ASEAN tentang masalah kemanusiaan di Rakhine, menekankan akan perlunya membentuk satuan tugas untuk menangani "situasi krisis dan darurat mengenai perpindahan penduduk yang tidak biasa di Asia Tenggara." Dalam pernyataan tersebut terlihat ASEAN menahan diri untuk tidak menyebut "Rohingya", melainkan merujuk pada minoritas Muslim yang tidak memiliki kewarganegaraan sebagai "korban dan komunitas yang terkena dampak konflik (Lee, 2018). Hal ini dikarenakan pemerintah Myanmar menolak penggunaan kata Rohingya dalam pertemuan tersebut. Perlakuan seperti ini dilakukan ASEAN agar menjaga keharmonisan anggotanya sehingga tidak mengancam status keanggotaan. Sehingga mekanisme penerapan ASEAN Way kembali lagi ke tujuan awalnya untuk menjaga kestabilan kondisi politik di kawasan asia tenggara dengan empat poin prinsip yang sudah dijelaskan sebelumnya. Di sisi lainnya, mekanisme diplomasi ASEAN ini membuat para anggotanya lebih sering melakukan kerja sama bilateral informal tanpa melibatkan ASEAN. Hal ini terjadi karena dianggap lebih mudah dan lebih longgar dalam pelaksanaannya. Pemikiran tersebut juga menjadi salah satu pertanyaan tentang tingkat efektivitas dari ASEAN Way of Diplomacy itu sendiri. 


\section{Kudeta Myanmar}

Myanmar Coup atau Kudeta Myanmar merupakan sebuah keadaan darurat yang diumumkan oleh militer Myanmar setelah menggulingkan pemerintahan Aung San Suu Kyi, kondisi darurat tersebut diumumkan oleh Militer Myanmar selama 1 tahun dimulai sejak tanggal 1 Februari 2021 sejak terpilihnya kembali partai National League for Democracy (NLD) yang diketuai oleh Suu Kyi. Myanmar sendiri merupakan sebuah negara di wilayah bagian Asia Tenggara berbatasan dengan Thailand, China, Laos, Bangladesh dan India dengan 54 juta masyarakatnya (Cuddy, 2021).

Tatmadaw, angkatan bersenjata Myanmar yang mengambil alih kekuasaan Aung San Suu Kyi, dilatarbelakangi atas ketidakpuasan hasil pemilu yang dimenangi oleh NLD di bulan November lalu, namun menurut militer Myanmar hasil pemilu tersebut dilakukan secara tidak adil (Nikkei Asia, 2021). Myanmar yang dulu dikenal juga sebagai Burma telah berjuang semenjak kemerdekaannya untuk melawan pemerintahan militer, kemiskinan, dan juga kelompok etnis minoritas di wilayahnya. Di tahun 2011 junta militer dibubarkan, pada awalnya hal ini diharapkan dapat memberikan transisi pemerintahan yang lebih baik khususnya di wilayah Asia Tenggara, namun pihak Tatmadaw selalu ikut serta khususnya di dalam aspek kebijakan dalam negeri Myanmar, salah satu intervensi militer Myanmar adalah melakukan genosida terhadap muslim Rohingya di wilayah barat, Rakhine (Maizland, 2021). Pengambilan kekuasaan yang dilakukan militer Myanmar telah mendorong masyarakat untuk turun kejalan guna melakukan aksi protes penolakan, kudeta yang dilakukan militer Myanmar dalam kurung waktu satu minggu telah menciptakan Dewan Administrasi Negara bersama Min Aung Hlaing dan mengisi beberapa jabatan menteri, militer Myanmar juga memutus sambungan internet di wilayahnya, sehingga masyarakat tidak dapat menyampaikan aspirasi di media sosial khususnya di kota-kota besar (Tran, 2021).

Keadaan yang terjadi di Myanmar telah menciptakan protes yang menyatukan berbagai golongan masyarakat, protes tersebut merupakan sebuah penolakan masyarakat Myanmar yang akan hidup dalam pimpinan militer selama setahun kedepan. Kudeta yang terjadi di Myanmar sejak 1 Februari lalu telah menewaskan hampir 138 orang demonstran di wilayah Yangon, PBB juga menyatakan bahwa militer Myanmar telah melanggar hak asasi manusia (DW, 2021). Kondisi yang dihadapi oleh Myanmar saat ini, tidak hanya memberikan pengaruh terhadap urusan dalam negerinya saja, namun 
juga memberikan dampak yang besar bagi negara-negara yang memiliki hubungan bilateral dengan Myanmar. Sejak kudeta di Myanmar berlangsung, pabrik-pabrik yang dimiliki oleh China telah dibakar oleh para demonstran, setidaknya 38 orang tewas dalam pembakaran pabrik tersebut, hal tersebut dilatarbelakangi kecurigaan para pengunjuk rasa anti kudeta terhadap China, menurut mereka Beijing mendukung kudeta dan junta militer yang sedang terjadi saat ini (Regan, 2021).

Kudeta di Myanmar telah memberikan dampak bagi seluruh negara, khususnya ASEAN, ASEAN sendiri merupakan organisasi regional yang memiliki prinsip non-intervensi, namun dalam kondisi kudeta yang dihadapi Myanmar, ASEAN sudah seharusnya memberikan solusi dan jalan keluar bagi Myanmar. Menurut beberapa pakar politik, kudeta yang terjadi di Myanmar akan berdampak terhadap blok jika komunitas internasional tidak mengambil tindakan yang tegas, bahkan kondisi tersebut dapat memperburuk kondisi etnis Rohingya, kondisi terburuk lainnya adalah masyarakat yang akan keluar dari Myanmar sama seperti kondisi politik di tahun 1988, poin yang terpenting adalah kudeta yang dilakukan militer Myanmar telah melanggar prinsip ASEAN (Idrus, 2021). Pada akhirnya, kudeta yang terjadi di wilayah Myanmar saat ini akan lebih memberikan dampak bagi wilayah regional, adanya kemunduran demokrasi disaat yang bersamaan khususnya bagi negara-negara di wilayah Asia Tenggara akan menyebabkan sebuah ketidakstabilan regional, selain itu hal tersebut mungkin akan melahirkan pemberontakan baru di wilayah Myanmar guna mengakhiri kudeta yang terjadi saat ini (Kurlantzick, 2021).

\section{Pengambilan Kebijakan ASEAN Dalam Menghadapi Kudeta Myanmar}

ASEAN saat ini masih menghadapi persoalan dalam pendekatan keputusan yang harus mereka ambil mengenai kudeta militer Myanmar. Hal ini dapat terlihat dari perbedaan pandangan sesama negara anggota seperti bagaimana Indonesia, Singapura, dan Malaysia secara publik mencetuskan kekhawatiran mereka terhadap kudeta yang terjadi di Myanmar (Strangio, 2021), namun beberapa negara anggota seperti Thailand, Kamboja dan Vietnam cenderung masih lebih memilih untuk berdiri pada prinsip non-interferensi. Indonesia sendiri sebagai salah satu negara yang cukup vokal dalam menyuarakan kekhawatirannya terhadap kudeta di Myanmar telah melakukan beberapa upaya dalam 
mendorong ASEAN untuk mengambil tindakan terhadap krisis kudeta yang melanda Myanmar dibawah direksi menteri luar negeri Indonesia-Retno Marsudi.

Pada awalnya Retno Marsudi telah memiliki agenda untuk mengunjungi Myanmar dan berbicara kepada para petinggi pemberontak militer, namun di dalam salah satu dokumen pemerintahan terdapat kebocoran informasi mengenai agenda kedatangan Retno Marsudi ke Myanmar dibatalkan dikarenakan agenda pertemuan tersebut seharusnya privat dan tidak diketahui publik (Reuters Staff, 2021).

Namun, kegagalan tersebut tidak membuat upaya Retno Marsudi terhenti, tetapi beliau justru semakin menjalankan misinya dalam pembentukan dukungan dari negara anggota ASEAN lainnya dengan tujuan terjadinya special summit antara para petinggi ASEAN dalam menindaki kasus kudeta militer Myanmar (Haan, 2021). Dua minggu setelah kudeta tersebut terjadi, Retno Marsudi sudah memulai kunjungannya untuk mengumpulkan support dimulai dari Brunei yang kemudian dilanjutkan ke Singapura (Strangio, 2021). Vivian Balakrishnan selaku menteri luar negeri Singapura juga mendukung agenda Retno Marsudi. Di dalam jawaban tertulisnya, Vivian Balakrishnan menegaskan bahwa
ASEAN memiliki Piagam ASEAN serta Deklarasi Hak Asasi Manusia ASEAN dan beliau berharap bahwa negara anggota lainnya menghargai tujuan dan prinsip yang ada di dalamnya (Ministry of Foreign Affairs Singapore, 2021). Namun, beliau juga melanjutkan bahwa dengan adanya prinsip non-interferensi yang dipegang oleh ASEAN, maka negara anggota yang proaktif dalam mengusung isu kudeta militer Myanmar tidak bisa memaksa anggota lainnya untuk melakukan hal yang sama. Jawaban Vivian Balakrishnan sangat mencerminkan bagaimana negara anggota ASEAN berada di kondisi yang sulit untuk mengambil kebijakan mengenai isu Myanmar karena perbedaan pendapat yang berakar pada prinsip non-interferensi ASEAN.

Upaya ASEAN untuk isu kudeta militer di Myanmar saat ini masih berada pada desakan agar Aung San Suu Kyi selaku pemimpin de facto Myanmar segera dilepaskan oleh pihak militer (VOA News, 2021). Selain itu juga ASEAN telah memberikan himbauan perdamaian kepada Myanmar terutama mengingat banyaknya pelanggaran hak asasi manusia yang dilakukan sepanjang kudeta yang sedang berlangsung dengan terbunuhnya puluhan demonstran (Idrus, 2021). Dengan pelanggaran hak asasi manusia yang terjadi di Myanmar dan sanksi yang 
dilayangkan oleh Amerika Serikat dan EU (European Union), pada hakikatnya ASEAN juga memiliki hak untuk memberi sanksi terhadap militer Myanmar yang melakukan kudeta dan pelanggaran hak asasi manusia. Namun pengambilan kebijakan berupa sanksi bukanlah strategi yang bisa dilakukan begitu saja oleh ASEAN dan akan ada banyak suara yang menyatakan ketidaksetujuan dari negara anggota karena bagaimanapun juga mereka harus menghormati prinsip non-interferensi (Haan, 2021).

ASEAN hingga saat ini masih mengusahakan pendekatan dalam pengambilan kebijakan melalui dialog konstruktif yang telah diberikan melalui pernyataan dari hasil IAMM (Informal ASEAN Ministerial Meeting) pada tanggal 2 Maret 2021 yang dihadiri oleh seluruh menteri luar negeri negara anggota ASEAN termasuk di dalamnya menteri luar negeri baru dari pihak militer Myanmar (Tan, 2021). Di dalam chair's statement No. 8 pada IAMM (ASEAN, 2021), ASEAN telah meminta seluruh pihak militer Myanmar untuk menahan diri dan kekerasan yang tengah terjadi harus segera dihentikan. Selain itu, Brunei Darussalam selaku chairmanship ASEAN pada tahun ini juga menyatakan bahwa mengenai isu kudeta militer Myanmar, ASEAN akan ikut proaktif membantu dalam isu ini tetapi dengan cara-cara yang damai, bermanfaat, dan positif.

\section{KESIMPULAN}

ASEAN merupakan organisasi regional yang memiliki reputasi tersendiri di dalam berbagai aspek yang didukung oleh prinsip-prinsip dasar yang mereka bentuk dan pegang teguh sejak dulu. Memang jika dilihat secara nilai, prinsip-prinsip ASEAN merupakan suatu fondasi kuat dan bijak. Secara garis besar prinsip-prinsip dasar ASEAN memiliki nilai-nilai seperti saling menghormati, positif, damai, terbuka dan menjunjung tinggi hukum internasional. Namun, ketika dihadapkan dengan sebuah isu internal beberapa nilai yang terkandung di dalam prinsip-prinsip dasar ASEAN justru menjadi seperti kutub magnet yang berlawanan.

Melihat dari situasi kudeta militer Myanmar yang terjadi hingga saat ini, nilai untuk saling menghormati dengan nilai menjunjung tinggi hukum internasional pun menjadi tidak cocok. Kita mengetahui bahwa kudeta militer Myanmar telah melanggar hukum internasional dikarenakan menggunakan kekerasan dan membuat banyak korban jiwa berjatuhan. Bahkan, tindakan yang dilakukan oleh militer Myanmar ini sudah dijatuhi sanksi oleh Amerika Serikat dan Uni Eropa. ASEAN sebagai sebuah organisasi regional memiliki prinsip 
bahwa mereka akan menjunjung piagam PBB serta hukum internasional, selain itu ASEAN juga ber-prinsip bahwa mereka akan bekerja sama dalam menjaga keamanan bersama di wilayah Asia Tenggara. Tetapi disaat bersamaan ASEAN juga memiliki beberapa prinsip saling menghormati yang didalamnya terdapat sebuah prinsip yang cukup kompleks-prinsip noninterferensi.

Jika dilihat dari rekam jejak ASEAN, kita dapat melihat bagaimana ASEAN memiliki kerjasama yang baik di bidang politik, ekonomi, dan security. Dengan berdirinya APC, AIPR, ACCT, AEC, dsb., telah menjadi sebuah aktualitas dari hasil pola kerjasama ASEAN yang kolektif dan terkoordinir. Namun juga dengan berbagai data yang tersedia, kerjasama ASEAN kerap kali di cap lambat dalam membenahi isu internal yang terjadi kepada negara anggotanya. Di dalam isu kudeta militer Myanmar sendiri ASEAN pada awalnya mengalami situasi dimana pendapat antar negara anggota terpecah. Beberapa negara anggota menyatakan kekhawatirannya dan ingin ASEAN untuk ikut andil dalam isu yang tengah panas tersebut, tetapi beberapa negara anggota lainnya berpendapat bahwa kudeta Myanmar merupakan urusan internal Myanmar dan mereka tidak boleh mengintervensi hal tersebut sesuai dengan prinsip ASEAN yang selalu mereka pegang teguh.

Tetapi isu kudeta militer di Myanmar dapat dikatakan sudah diluar kendali mengingat kekerasan yang digunakan dan banyaknya korban berjatuhan dimana hal itu melanggar HAM masyarakat yang bersangkutan. Jika terus dibiarkan, isu ini diperkirakan dapat semakin membesar dan prestise ASEAN sebagai sebuah organisasi regional juga akan terpengaruh. Akan tetapi, ASEAN mengkaji pendekatan kebijakan mereka melalui diplomasi ASEAN Way yang terdiri atas the principles of noninterference in the internal affairs of other members, quiet diplomacy, the non-use of force, dan decision-making through consensus. Dimulai dari melakukan konsensus melalui IAMM pada tanggal 2 Maret 2021, ASEAN mengambil kebijakan subtil dengan memberikan desakan kepada pihak militer Myanmar untuk membebaskan Aung San Suu Kyi dan permintaan untuk menghentikan kekerasan yang dilakukan oleh pihak militer kepada pihak masyarakat. Melalui desakan dan himbauan perdamaian tersebut, ASEAN dapat memberikan upaya dengan secara halus untuk membantu isu kudeta militer di Myanmar tanpa melanggar prinsip non-interferensi ASEAN namun juga tidak mengabaikan hukum internasional yang dilanggar oleh pihak militer 
dengan melakukan kekerasan kepada masyarakat Myanmar.

Dikarenakan isu kudeta tersebut masih belum terselesaikan dan kebijakan yang diberikan oleh ASEAN dapat dibilang masih di tahap permulaan membuat tulisan ini juga menjadi sebuah analisis awal dalam isu tersebut. Walaupun dengan desakan dan himbauan yang telah dilakukan ASEAN, tentu saja hal tersebut belum cukup untuk menghentikan krisis yang terjadi di Myanmar saat ini. Sehingga, kami menyarankan agar penelitian selanjutnya untuk menganalisis progres dari isu kudeta yang terjadi dan perkembangan kebijakan yang dilakukan oleh ASEAN dalam menghadapinya terutama melihat bagaimana ASEAN belum memberikan kebijakan yang tegas terhadap isu kudeta militer di Myanmar.

\section{REFERENSI}

ASEAN Secretariat. (n.d) History of ASEAN (Online). Available at: https://asean.org/asean/aboutasean/history/

(Accessed: 11 March 2021).

ASEAN Secretariat. (2009) ASEAN Political - Security Community (Online). Available at: https://asean.org/aseanpolitical-security-community/ (Accessed 13 March 2021).

ASEAN Secretariat. (2016) Treaty of Amity and Cooperation in Southeast Asia Indonesia, 24 February 1976 (Online). Available at: https://asean.org/treatyamity-cooperation-southeast-asia- indonesia-24- february-1976/

(Accessed 17 Maret 2021).

ASEAN Secretariat. (2021) Chair's Statement on the Informal ASEAN Ministerial Meeting (LAMM) 2 March 2021

(Online). Available at: https://asean.org/storage/FINALChairmans-Statement-on-theIAMM.pdf (Accessed 18 March 2021).

ASEAN Secretariat. (2007) The Asean Charter. s.l. ASEAN Secretariat.

Chia, S.Y \& Plummer, M.G. (2015) ASEAN Economic Cooperation and Integration Progress, Challenges and Future Directions. Cambridge University Press.

Cuddy, A. (2021) Myanmar Coup: What is Happening and Why? (Online). Available at: https://www.bbc.com/news/worldasia-55902070 (Accessed: 13 March 2021).

Cuyvers, L. (2019) "The 'ASEAN Way' and ASEAN's Development Gap With Cambodia, Laos, Myanmar and Vietnam: A Critical View". Asia Pacific Business Review, 23 August, 25(5), pp. 683-704.

DW. (2021) Myanmar: 56 Dead Over Weekend, 138 Since Coup, Says UN (Online). Available at: https://www.dw.com/en/myanmar56-dead-over-weekend-138-sincecoup-says-un/a-56881039 (Accessed: 11 March 2021).

Mansfield, E.D., Milner, H.V. (2003) The New Wave of Regionalism. Cambridge University Press.

Goldman, R. (2021) Myanmar's Protests, Explained. New York Times, 4 March.

Haan, J. D. (2021) "Can Indonesia Rally an ASEAN Response to the Myanmar Coup?". Future Directions International, 24 February.

Head, J. (2021) Myanmar Coup: Aung San Sun Kyi Detained As Military Seizes Control (Online). Available at: 
https://www.bbc.com/news/worldasia-55882489 (Accessed: 1 February 2021).

Idrus, P. G. (2021) Myanmar Coup May Destabilize ASEAN: Experts (Online). Available at: https://www.aa.com.tr/en/asiapacific/myanmar-coup-maydestabilize-asean-experts/2134105. (Accessed: 04 February).

Indratno, B. (2009) "Analisis Lingkungan Eksternal: Kerjasama Ekonomi Masyarakat Asean". media neliti, Volume 12, pp. 180-230.

J. B. S. S. (2005) European Integration and Regional Cooperation. 3rd ed. New York: Oxford University Press.

KEMENLU RI. (2015) Masyarakat Politik Keamanan ASEAN (Online). Available at: http://www.kemlu.go.id/id/kebijakan /asean/Pages/MasyarakatPolitikKea mananASEAN.aspx (Accessed: 13 March 2021).

Katanyuu, R. (2006) "Beyond NonInterference in ASEAN: The Association's Role in Myanmar's National Reconciliation and Democratization". Asian Survey, Vol. 46, No. 6.

Katsumata, H. (2003) "Reconstruction of Diplomatic Norms in Southeast Asia: The Case for Strict Adherence to the " ASEAN Way". Contemporary Southeast Asia, April, 25(1), pp. 1 04-121.

Kurlantzick, J. (2021) The Regional Implications of Myanmar's Coup (Online). Available at: https://aspeniaonline.it/theregional-implications-of-myanmarscoup/ (Accessed: 12 February).

Fawcett, L., Hurrell, A. (1992) Regionalism in World Politics: Regional Organization and International Order. New York : Oxford University Press.

Lee, H. Y. (2018) ASEAN's Limited Role in Solving the Rohingya Crisis (Online).
Available at:

https://thediplomat.com/2018/10/as eans-limited-role-in-solving-therohingya-crisis/ (Accessed: 18 Maret 2021).

Lentner, H. H. (1974) Foreign Policy Analysis, A Comparative and Conceptual Approach. Bell \& Howell Company.

Ministry of Foreign Affairs of Singapore. (2021) Minister for Foreign Affairs Dr Vivian Balakrishnan's Written Replies to Parliamentary Questions, 16 February 2021 (Online). Available at: https://www.mfa.gov.sg/Newsroom/ Press-Statements-Transcripts-andPhotos/2021/02/20210216-Writtenreplies-to-PQs (Accessed: 18 March 2001).

Maizland, L. (2021) Myanmar's Troubled History: Coups, Military Rule, and Ethnic Conflict (Online). Available at: https://www.cfr.org/backgrounder/ myanmar-history-coup-military-ruleethnic-conflict-rohingya (Accessed 18 March 2021).

Nikkei Asia. (2021) Myanmar Coup Latest: Protester Death toll Tops 180, Says Activist Group (Online). Available at: https://toysmatrix.com/myanmarcoup-latest-protester-death-toll-tops180-says-activist-group/(Accessed: 22 February).

Reuters Staff. (2021) Indonesian Minister To Fly To Myanmar In First Foreign Envoy Visit Since Coup: Document (Online). Available at: https://www.reuters.com/article/usmyanmar-politics-indonesiaidUSKBN2AN1K1 (Accessed: 23 February 2021).

Regan, H. (2021) Chinese factories set on fire and at least 38 killed in Myanmar's Deadliest Day Since Coup (Online). Available at: https://edition.cnn.com/2021/03/15 /asia/myanmar-deaths-chinesefactories-intl-hnk/index.html (Accessed: 15 March 2021). 
Rosenau, J. N. (1999) Kamus Hubungan Internasional. Abardin.

SETNAS-ASEAN. (2019) Ayo Kenali ASEAN. Kementrian Luar Negeri RI.

Smith, M. (1997) Region and Regionalsm. Macmillan Publishers Limited.

Strangio, S. (2021) Indonesia Leading ASEAN Push on Myanmar Coup (Online).

Available at: https://thediplomat.com/2021/02/in donesia-leading-asean-push-onmyanmar-coup/ (Accessed: Februari, 2021).

Söderbaum, F. (2014) Regionalism. researchgate, 18 February.

Tan, C. (2021) To Save Myanmar and Itself, ASEAN must be Bold (Online).

Available at: https://intpolicydigest.org/to-save- myanmar-and-itself-asean-must-bebold/ (Accessed: 10 March 2021).

Tran, V. (2021) To understand post-coup Myanmar, look to its history resistance - not sanctions (Online). Available at: https://www.brookings.edu/blog/or der-from-chaos/2021/02/09/tounderstand-post-coup-myanmar-lookto-its-history-of-popular-resistancenot-sanctions / (Accessed: 9 February 2021).

VoA News. (2021) ASEAN Urges Peaceful Solution to Myanmar Coup Standoff (Online). Available at: https://www.voanews.com/east-asiapacific/asean-urges-peaceful-solutionmyanmar-coup-standoff (Accessed: 02 March 2021).

Webber, M. \& Smith, M. (2002) Foreign Policy in Transformed World. Routledge. 